\section{Assessment of portable X-ray fluorescence analysis for the evaluation of slate procurement and exchange: a Maritime Archaic case study from Newfoundland and Labrador}

\author{
Christopher B. Wolff, ${ }^{1}$ \\ Robert J. Speakman, ${ }^{2}$ \\ William W. Fitzhugh ${ }^{3}$
}

'Department of Anthropology, State University of New York, Plattsburgh, NY; ${ }^{2}$ Center for Applied Isotope Studies, University of Georgia, Athens, GA; ${ }^{3}$ Department of Anthropology, National Museum of Natural History, Smithsonian Institution, Washington, DC, USA

\section{Abstract}

Prehistoric peoples of Newfoundland and Labrador, like many northern coastal populations, produced many of their stone tools from slate; however, the procurement and movement of this material in that Province and elsewhere has gone virtually unstudied beyond generalised typologies and macroscopic evaluation. This paper provides an overview of a recent study utilising non-destructive portable $\mathrm{X}$-ray fluorescence (pXRF) technology to analyse slates used by people of the Maritime Archaic tradition (ca. 8000-3200 BP) in Newfoundland and Labrador. Because pXRF is non-destructive, these instruments allow archaeologists to chemically analyse artifacts directly in non-traditional laboratory environments. Through the examination of 164 slate artifacts recovered from 50 sites from throughout Newfoundland and Labrador, we were successful at identifying broad regional patterns in slate distribution, as well as identifying preferred use of particular slate varieties in the production of specific artifact classes. Although limitations exist in the use of this technology, mostly having to do with the physical nature of the source material and the appropriate scale of research, this study demonstrates its potential in identifying broad use patterns and distribution of slate in ancient exchange systems.

\section{Introduction}

The Maritime Archaic people occupied much of Newfoundland and Labrador for more than 4000 years (ca. 8000-3200 BP) (Fitzhugh
1975, 1978, 2006; Hood, 1993; McGhee and Tuck, 1975; Tuck, 1976, 1977; Renouf, 1999; Wolff, 2008). During that time a distinct variety of chert, locally known as Ramah chert, became an important component of the material culture. The only geologic sources for this material are found in northern Labrador, at Ramah Bay (Figure 1), yet it has been found throughout the known Maritime Archaic range and beyond, making it as far south as New England (Gramly, 1978; Lazenby, 1980; Loring, 2002). However, there has been little systematic research that has examined what other commodities may have been part of the long-distance exchange-procurement system that facilitated the movement of Ramah chert. Due to the high acidity in the soils of North America's eastern Subarctic, most organic commodities are not well preserved in that region, making it difficult to test whether bone, wood, or other organic materials were traded. For that reason, we chose to examine the procurement and distribution of slate, one of the only other lithic materials that was extensively used by the Maritime Archaic and found throughout their known range. In this study, we evaluate possible long-distance movement of slate and its relationship to larger exchange networks. We also test the utility of an increasingly used technology, portable X-ray fluorescence (pXRF), in the assessment and identification of slate varieties used to create stone tools.

\section{Materials and Methods}

There were three major research questions we were interested in concerning the use of pXRF instruments and their utility to study slate procurement, exchange and distribution. First, could pXRF technology discriminate among slate varieties procured from discrete source locations? Second, if pXRF can be used to identify different slate varieties (e.g., geologic sources), are there observable patterns in the use of those varieties by the Maritime Archaic that relate to geography or chronology? And finally, if there are clear patterns in slate use, do they provide evidence for directionality of slate procurement and/or exchange as part of a larger economic system, perhaps involving the procurement of other exchange goods, particularly other lithic materials such as Ramah chert? To address these questions we analysed 164 samples from 50 Maritime Archaic sites from Newfoundland and Labrador housed at the National Museum of Natural History (NMNH) of the Smithsonian Institution and at The Rooms, Newfoundland and Labrador's Provincial Museum, using a Bruker AXS Tracer III-V handheld pXRF (Bruker, Billerica, MA, USA; Figure 2). All slate samples were analysed as unmodified samples. The instrument is
Correspondence: Christopher B. Wolff, Department of Anthropology, State University of New York, 101 Broad Street, 12901-2681 Plattsburgh, NY, USA.

Tel. +1.518.564.4005 - Fax: +1.518.564.3010.

E-mail: christopher.wolff@plattsburgh.edu

Key words: pXRF, slate, Newfoundland and Labrador, Maritime Archaic, lithics.

Acknowledgments: we would like to thank everyone at the Arctic Studies Center and the Museum Conservation Institution at the Smithsonian for their support of this project. We would also like to thank Elaine Anton and the staff at the Rooms, Provincial Museum of Newfoundland and Labrador for their support and access to their collections. Thanks also to Stephen Hull at the PAO in St. John's for providing maps and site data. Thanks to Elaine Anton and John Erwin for their hospitality during Wolff's visit to St. John's. Special thanks to Stephen Loring for access to his collections as well. And very special thanks to the Smithsonian for their postdoctoral fellowship support for this project.

Funding: this study was supported by a postdoctoral fellowship of the Smithsonian Institution, Washington, DC, USA.

Citation: Wolff CB, Speakman RJ, Fitzhugh WW, 2014. Assessment of portable X-ray fluorescence analysis for the evaluation of slate procurement and exchange: a maritime archaic case study from Newfoundland and Labrador. In: RH Tykot (ed.), Proceedings of the $38^{\text {th }}$ International Symposium on Archaeometry - May $10^{\text {th }}-14^{\text {th }}$ 2010, Tampa, Florida. Open Journal of Archaeometry 2:5460.

Presented at the $38^{\text {th }}$ International Symposium on Archaeometry - May $10^{\text {th }}-14^{\text {th }} 2010$, Tampa, Florida.

This work is licensed under a Creative Commons Attribution 3.0 License (by-nc 3.0).

(C) Copyright C.B. Wolff et al., 2014

Licensee PAGEPress, Italy

Open Journal of Archaeometry 2014; 2:5460

doi:10.4081/arc.2014.5460

equipped with a rhodium tube and a SiPIN detector with a resolution of $c a .170 \mathrm{eV}$ FHWM for $5.9 \mathrm{keV} \mathrm{X-rays} \mathrm{(at} 1000$ counts per second) in an area $7 \mathrm{~mm}^{2}$. Each sample was measured twice using different excitation conditions. For the first analysis, each sample was analysed at $40 \mathrm{kV}, 15 \mu \mathrm{A}$, with a 0.076 -mm copper filter and 0.0305 -mm aluminum filter placed in the X-ray path for a 200-second live-time count. Peak intensities for the $\mathrm{K}$ peaks of $\mathrm{Mn}, \mathrm{Fe}, \mathrm{Rb}, \mathrm{Sr}, \mathrm{Y}$, $\mathrm{Zr}$, Nb, and $\mathrm{L}$ peak of Th were calculated as ratios to the Compton peak of rhodium, and converted to parts-per-million (ppm) using linear regressions derived from the analysis of 15 obsidian reference samples. For the second 
analysis, each sample was analysed at $12 \mathrm{kV}, 15$ $\mu \mathrm{A}$, for a 200-second live-time count. Peak intensities for the $\mathrm{K}$ peaks $\mathrm{Al}, \mathrm{K}, \mathrm{Ti}$, and $\mathrm{K}$ peak of $\mathrm{Ca}$ were converted to parts-per-million (ppm) using linear regression derived from the analyses of Brill Glass A and B, USGS pressed powder standards (AGV-1, DNC-1, DTS-2, G-2, MAG-1, SDC-1, SD0-1, SGR-1, and $\mathrm{W}-2$ ), and several obsidian reference samples.

Samples were selected from every Maritime Archaic site represented in the collections of the NMNH and The Rooms that contained slate. If a site had a single slate artifact, that artifact was analysed. If collections from a site included multiple artifacts, samples were selected that represented a cross-section of the assemblage based on macroscopic variation (e.g. differences in color, grain-size, and tool type). In most cases the samples were formal tools; however, a handful of samples were flakes from collections where formal slate tools were not present. The formal tools that were sampled included celts, adzes, bayonets, projectile points, and plummets (Figure 3 ).

The primary goal for data analysis of the samples was to identify distinct groups within the datasets and examine intersite spatial patterning. These groups are assumed to represent geographically restricted sources. In the past, lithic raw materials were likely collected from both outcrops and/or secondary deposits; a.

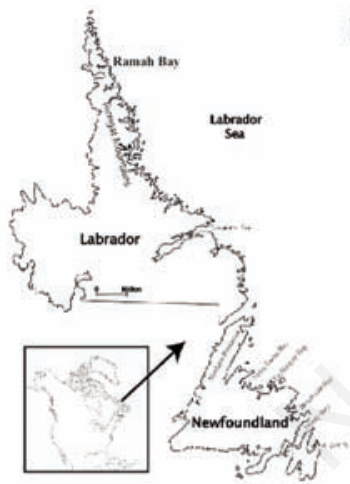

d.

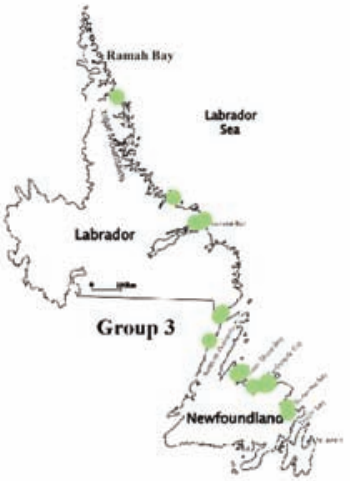

b.

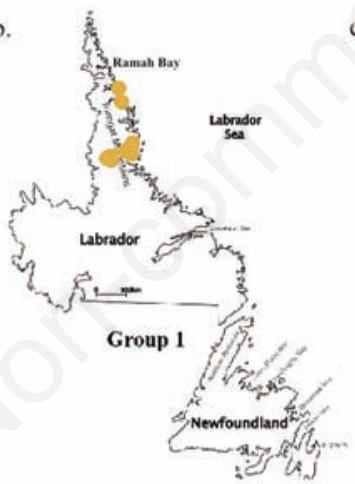

e.

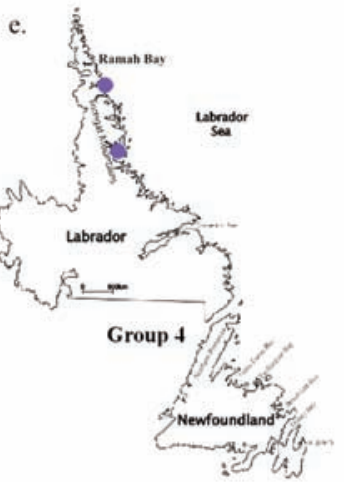

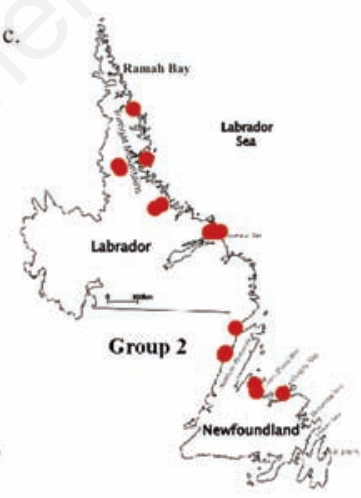

f.

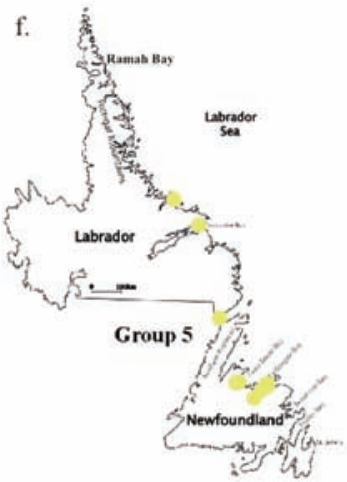

therefore, the compositional data obtained from the samples in our study was also an attempt to detect source localities or groups. The locations of these compositional groups, because of the lack of available modern source samples for this study, are inferred by indirect methods based on frequency of sample variety and assumptions based on distance decay modeling. Distance decay modeling is the idea that the farther people carry raw material from its procurement location, the less frequent that the procurers will be able to use the material because it will have been used up; therefore, formal tools will be found less frequently in archaeological deposits (Odell, 1996).

Groups are characterised by the locations of their compositional centroids and the unique relationships (i.e., correlations) between their chemical signatures, focusing on several elements that earlier testing found to be the most useful in discerning compositional groups, and which could be accurately quantified by pXRF. These elements included Ca, K, Ti, Sr, Y, Zr, Rb, $\mathrm{Nb}, \mathrm{Fe}$, and Ga. Decisions about assigning samples to a particular compositional group were based on inherent patterning observed in element plots and principal component space and confirmed via the use of Mahalanobis distance probabilities.

\section{Results and Discussion}

The resulting data suggests interesting patterns in the long-distance movement of slate throughout Newfoundland and Labrador. Principal component analysis focused on the elements, $\mathrm{Ca}, \mathrm{K}, \mathrm{Ti}, \mathrm{Sr}, \mathrm{Y}, \mathrm{Zr}, \mathrm{Rb}, \mathrm{Nb}, \mathrm{Fe}$, and $\mathrm{Ga}$, demonstrated five discernible varieties of slate (Figure 4) we have simply named Groups 1-5 (Table 1). These were assessed using element plots and principal component space, and confirmed using Mahalanobis distance probabilities. There was also some unidentified specimens that had chemical signatures that did not fit well into these groups and were considered unidentifiable (Group U).

Despite what we believe to be the identification of the use of at least five to six varieties of slate by the Maritime Archaic, it is our view that the resulting groups are at resolution that is not useful for the examination of short-distance mobility in Newfoundland and Labrador. The success of our analysis is, in part, due to the long distances involved in the movement of lithic materials in the region, that spans five geological provinces, from roughly south to north: Appalachian (Newfoundland), St. Lawrence (Southern Labrador), Grenville (Central Labrador), Nain (Northern Labrador), and Churchill (Northern Labrador) (Geological Survey of Canada 1972).

When the five groups are mapped onto the landscape and correlated with the five geological provinces of Newfoundland and Labrador there is not a one-to-one correlation; neverthe-

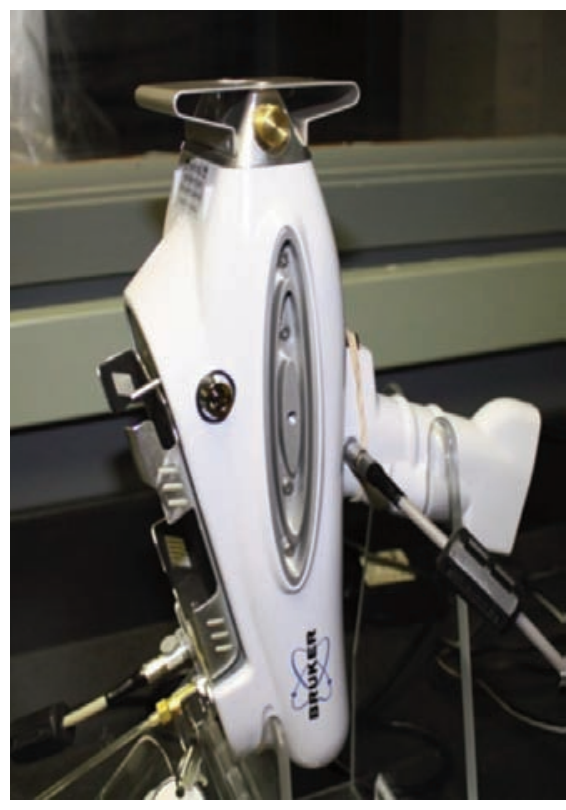

Figure 2. Bruker AXS tracer III-V handheld X-ray fluorescence spectrometer (Bruker, Billerica, MA, USA).

Figure 1. Site locations for each group: a) overall area considered in the study; b) group 1; c) group 2; d) group 3; e) group 4; e) group 4; f) group 5. 
less, there does appear to be a pattern that suggests most of the slate varieties have sources in the Appalachian geological province in the south and get distributed northward through exchange or possible direct long-distance procurement. Frequency analyses demonstrate that most slate varieties that were identified were found in higher numbers in geological provinces to the south on the island of Newfoundland and diminish in frequency as you move north (Table 1). When the sites are mapped on the landscape (Figure 5) the pattern suggests a northern movement of slate materials, with the exception of Group 1 $(n=13)$ and Group $4(n=4)$, both found solely in northern Labrador. Groups 1 and 4 were probably procured from northern local sources.

Chi-square analysis examining the relationship between artifact type and the slate groups demonstrated only one statistical correlation $\left(\mathrm{X}^{2}=27.82, \mathrm{P}<0.05, \mathrm{df}=15\right)$ between bifaces (defined here as non-projectile, cutting and processing tools) and slate groups 1 and 2, but the sample size was quite small $(n=9)$, making it difficult to interpret the pattern as a conscious decision by toolmakers to use those specific slate varieties to create bifacial cutting and processing tools. Although not statistically significant, it is intriguing that most bayonets and projectile points (79.2\%) were manufactured from southern sources (Supplementary Table 1), most likely from the island of Newfoundland, including artifacts found in northern assemblages, and more analyses are currently underway to understand if this pattern is cultural or if there are other possible reasons for the patterning. It could relate to physical properties of southern slate varieties (e.g. greater amount of quartzite) that make them able to keep a sharper edge than other varieties. One additional finding from this research is that macroscopic analysis alone is not adequate to separate slate varieties, as Figure 6 illustrates through refitting of a broken bayonet. If its three segments were found out of context, they would have likely thought to be fragments of three separate tools based on differences in their color. Portable XRF analyses verified they were from the same geologic source despite the color variation and differential weathering.

\section{Conclusions}

This study demonstrates that pXRF can be employed to distinguish among slate varieties at a geological scale that encompasses different geological provinces that include different depositional development of the original sedimentary parent material that led to the creation of the slate types. This limits the usefulness of pXRF analysis of slate artifacts in the assessment of exchange and procurement strategies of different peoples to cultures whose traditional ranges included multiple geological provinces, or who traded with people over long distances, such as the Maritime Archaic of Newfoundland and Labrador. Where we were able to document long distance transport of slate varieties during the Maritime Archaic period, it appears that the greatest amount of slate moved from south to north from Newfoundland up the Labrador coast. It
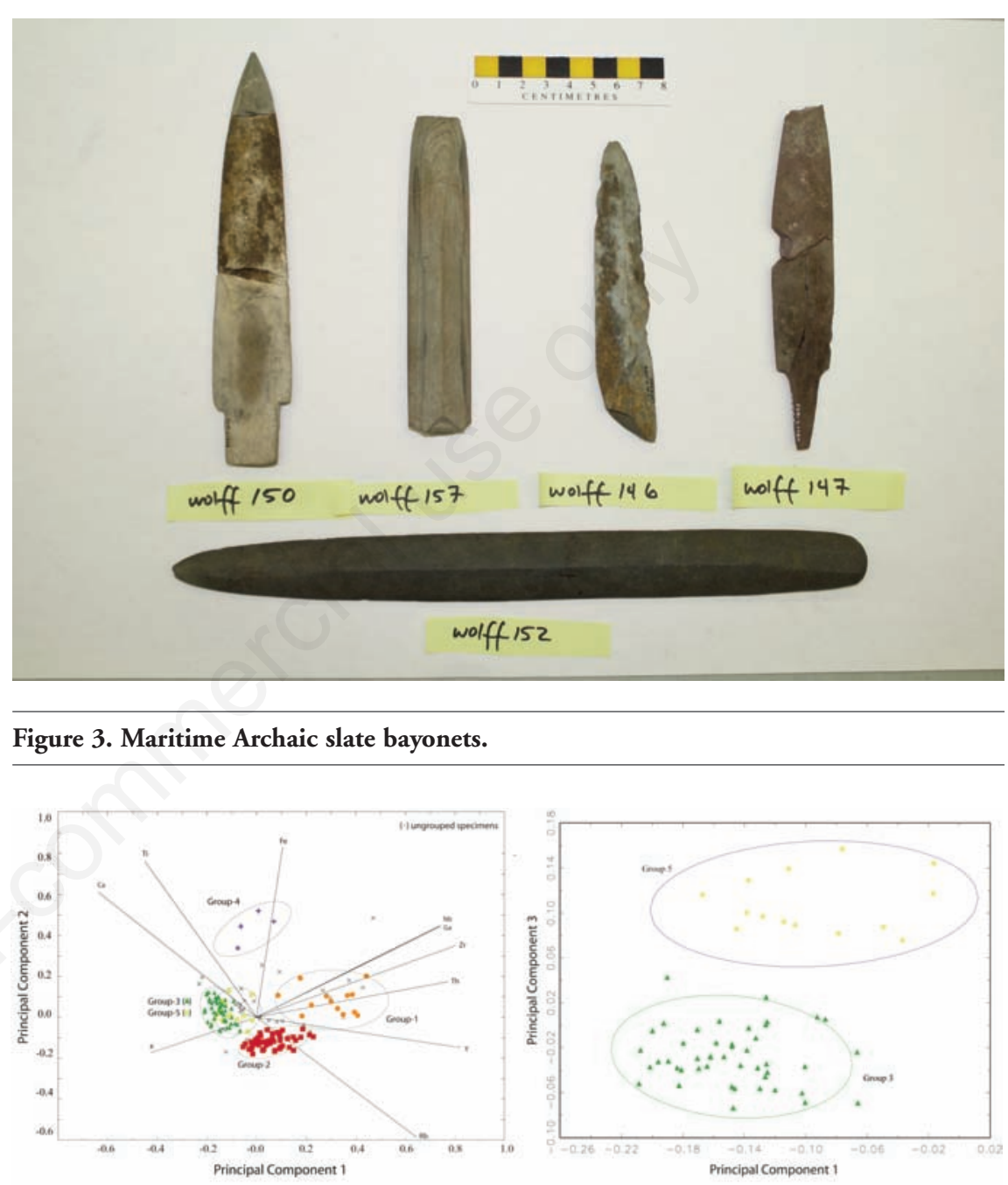

Figure 4. Principal component analyses of slate samples.

Table 1. Frequency of samples in each identified group and percentages for each region.

\begin{tabular}{|c|c|c|c|c|c|}
\hline Group & No. of samples & Northern Labrador ( $\%)$ & Central Labrador (\%) & Southern Labrador ( $\%)$ & Newfoundland (\%) \\
\hline 1 & 13 & 100 & 0 & 0 & 0 \\
\hline 2 & 52 & 20 & 19 & 21 & 40 \\
\hline 3 & 46 & 9 & 17 & 15 & 59 \\
\hline 4 & 4 & 100 & 0 & 0 & 0 \\
\hline 5 & 14 & 7 & 7 & 7 & 79 \\
\hline $\mathrm{U}$ & 35 & 26 & 20 & 31 & 23 \\
\hline
\end{tabular}

$\mathrm{U}$, unidentifiable. 


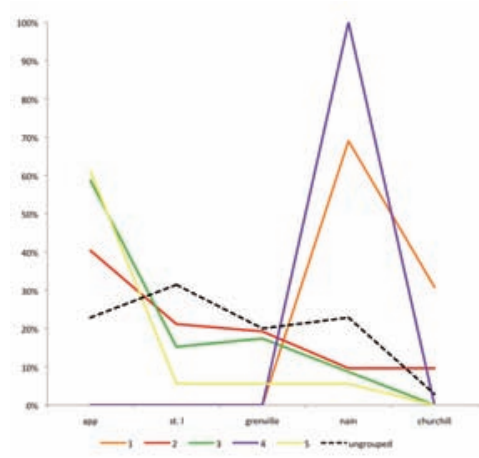

Figure 5. Percentage of samples from each group arranged by geological province from South to North (left to right).

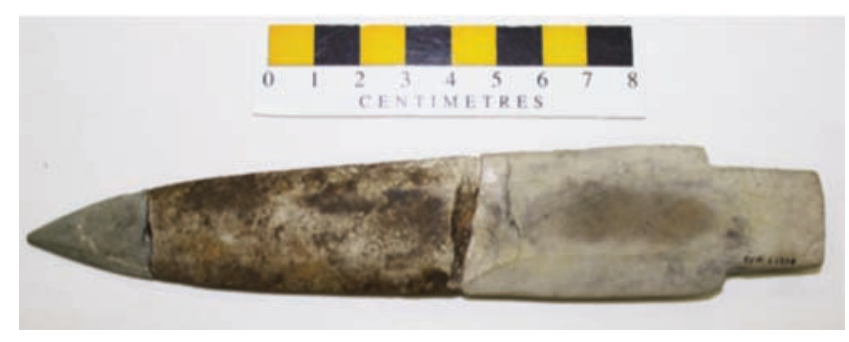

Figure 6. Refitted slate bayonet displaying differential taphonomy. also appears that in most, if not all, places within the Maritime Archaic range, people were also utilising local slate varieties. There is no evidence to date of northern slate varieties being transported or traded to the south beyond the central Labrador coastline.

Although this research is still in its infancy and far from conclusive, it suggests that the northern movement of slate could have played an important role in the Maritime Archaic economic system that included the southern movement and exchange of Ramah chert, perhaps the most important lithic material used by the Maritime Archaic, and the majority of later groups that occupied this region. The movement of Ramah chert from its source in northern Labrador to points south is vast, showing up as far south as New England, and must have been a major component of longdistance exchange networks for prehistoric groups of Newfoundland and Labrador; however, for what it was traded is still unknown. The research presented here raises the possibility that slate may have been at least one of the commodities that was exchanged for Ramah chert, yet much more needs to be done to test this hypothesis.

Finally, this study demonstrated that macroscopic identification of slate varieties based on color and texture is not always an accurate indicator of source. Differential taphonomic processes even within a single site can affect physical characteristics of slate artifacts-and all other artifacts - in a way that would cause them to be misidentified as originating from different sources. This suggests that chemical analyses such as pXRF, when available, can be a useful tool to, at the very least, check results of macroscopic identification of slate varieties. We suspect that the same case could be made for other artifact classes and raw materials as well, as long as the limitations of this technology is understood and acknowledged.

\section{References}

Fitzhugh WW, 1975. A Maritime Archaic sequence from Hamilton Inlet, Labrador. Arctic Anthropol 12:117-38.

Fitzhugh WW, 1978. Maritime Archaic cultures of the Central and Northern Labrador coast. Arctic Anthropol 15:61-95.

Fitzhugh WW, 2006. Settlement, social and ceremonial change in the Labrador Maritime Archaic. In: D. Sanger and M.A.P. Renouf (eds.) The Archaic of the Far Northeast. The University of Maine Press, Orono, ME, USA, pp 47-82.

Gramly RM, 1978. Lithic source areas in Northern Labrador. Arctic Anthropol 15:3647.

Hood BC, 1993. The Maritime Archaic Indians of Labrador: investigating prehistoric social organization. Newfoundland Studies 9:163-84.

Lazenby MEC, 1980. Prehistoric sources of chert in Northern Labrador: field work and preliminary analysis. Arctic 33:628-45.

Loring S, 2002. And they took away the stones from Ramah: lithic raw material sourcing and Eastern Arctic archaeology. In: W. Fitzhugh, S. Loring, D. Odess (eds.) Honoring our elders: a history of Eastern Arctic archaeology. Arctic Studies Center, National Museum of Natural History, Smithsonian Institution ed., Washington, DC, pp 163-186.

McGhee R, Tuck JA, 1975. An archaic sequence from the Strait of Belle Isle, Labrador. National Museum of Man ed., Ottawa, Canada.

Odell GH, 1996. Economizing behavior and the concept of "curation". In: G.H. Odell (ed.) Stone tools: theoretical insights into human prehistory. Plenum Press, New York, NY, pp 51-80.

Renouf MAP, 1999. Prehistory of Newfoundland hunter-gatherers: extinctions or adaptations? World Archaeol 30:403-20.

Tuck JA, 1976. Ancient people of Port au Choix. The excavation of an archaic Indian cemetery in Newfoundland. Institute of Social and Economic Research, Memorial University of Newfoundland ed., St. John, Canada.

Tuck JA, 1977. Early cultures on the strait of Belle Isle, Labrador. Ann Ny Acad Sci 288:472-80.

Wolff CB, 2008. A study of the evolution of Maritime Archaic households in Northern Labrador. Department of Anthropology, Southern Methodist University ed., Dallas, TX, USA. 